\title{
HPTLC Profiles and Antioxidant Activities from Leaves to Green and Roasted Beans of Coffea Arabica
}

\author{
Corina Bubueanu ${ }^{1 *}$, Ramona Pavaloiu ${ }^{2}$, Lucia Pirvu ${ }^{3}$ \\ ${ }_{1,3}^{1,3}$ xtractive Biotechnologies, National Institute for Chemical Pharmaceutical Research and Development (ICCF-Bucharest), Vitan Avenue 112, \\ Sector 3, Bucharest, ROMANIA \\ ${ }^{2}$ Organic Synthesis Department, National Institute for Chemical Pharmaceutical Research and Development (ICCF-Bucharest), Vitan Avenue 112, \\ Sector 3, Bucharest, ROMANIA
}

*Email for Correspondence: corina.bubueanu@yahoo.com

\begin{abstract}
The health benefits of coffee consumption are a very actual research subject, given the fact that is one of the most popular beverages in the world. The majority of the studies are concentrated to coffee beans (green or roasted) chemical composition (the most important non-volatile compounds investigated being phenols and alkaloids) and pharmacological activity. Green coffee is now in the market in the form of food supplements products. In the present, the chemical composition and bioactivity of the leaves occupy a small place in scientific papers.

This research paper investigate, in terms of caffeine, phenolic compounds composition and antioxidant activities, the differences and similarities between hydroalcoholic extracts of Coffea arabica leaves and green and roasted beans. The extracts profiles, determined by HPTLC technique, shows the major phenolic compounds. Through chromatographic fingerprint, the presence and the amount of caffeine in the extracts were also determined. The total phenolic content (TPC) (Folin Ciocalteu method) expressed as gallic acid equivalents decrease from the leaves to green and roasted coffee beans extracts. The IC50 (concentration of sample required to inhibit $50 \%$ of the DPPH free radical) was determined by free radical scavenging activity of Dpph. The IC50 values were TPC concentration-dependent. The obtained results show that in the hydroalcoholic extracts of the leaves are almost the same major phenolic compounds as in the green coffee beans extract. Also, the leaves extract have a higher content in total phenols and a better antioxidant activity comparative to the other samples. Therefore, this paper can be the first step for further investigations of coffee leaves extracts, which might have important health beneficial effects and can be a reliable raw material for food supplements industry.
\end{abstract}

Key words: Coffea arabica, leaves, HPTLC

This article is is licensed under a Creative Commons Attribution-NonCommercial 4.0 International License.

Attribution-NonCommercial (CC BY-NC) license lets others remix, tweak, and build upon work non-commercially, and although the new works must also

acknowledge \& be non-commercial.

\section{INTRODUCTION}

Coffee is now, one of the most consumed drinks in the world. Coffee belongs to the Coffea genus, family Rubiaceae. From more of the 80 coffee species, there are only two commercially available: Coffea arabica (the most consumed one, known as Arabica) and Coffea canephora (known as Robusta). The health benefits of coffee consumption become one of the major scientific subjects, because of the chemical composition that includes phenolic compounds, carbohydrates, alkaloids, vitamins, volatile compounds and minerals. (Dong W, et al., 2015; Ballesteros LF, et al., 2015; Tuomilehto J., 2013; Adrian J, Frangne R. 1991; Folstar P, et al., 1977)

The main phenols in the coffee are chlorogenic acids with the major subclasses caffeoylquinic (CQA), feruloylquinic (FQA), and dicaffeoylquinic (diCQA) acids (Dupas, et al., 2006; Ochiai R, et al., 2014), and the most important alkaloids are caffeine and trigonelline (R.J. Clarke, R. Macrae, 1988; Hiroshi Ashihara, 2015). 
Chlorogenic acids are known for their antioxidant properties that play an important role in health, attributed to the benefic influence in a high number of medical problems, by fighting free radicals. They are associated with positive effects on several degenerative diseases, such as type 2 diabetes, coronary heart disease, Alzheimer's and Parkinson's diseases (Adrina Farah, Giselle Duarte, 2015; Somporn C, et al., 2012).

Caffeine is an adenosine - receptor antagonist that stimulates the central nervous system. The health effect of caffeine consumption is an actual research subject. A moderate intake of caffeine is associated with increased alertness and reduces fatigue while an excessive intake has can produces negative effects on health (Victor R. Preedy, 2012).

The majority of the study is made for green and roasted coffee, green beans being used in food supplement industry and the roasted one în the beverage. Having such important fruits, the leaves of the coffee tree can be an interesting research subject.

The objective of this paper is to investigate the chemical composition in major compounds and antioxidant properties, of coffee leaves comparative with green and roasted beans.

\section{Materials AND Methods}

Chemicals. References substances: caffeic acid, chlorogenic acid, rutin, hyperoside, caffeine (Sigma Chemical Co., St. Louis, USA), Folin-Ciocalteu's Phenol reagent, NP - natural product (Fluka), PEG - polyethylene glycol (Fluka), 2,2diphenyl-1-picrylhydrazyl (DPPH) (Sigma), sodium molybdate, ammonium phosphate, methanol and ethanol HPLC grade, sulfuric acid, ethyl acetate, acetic acid, formic acid.

Preparation of extracts. The raw material (roasted beans, green beans and leaves (for one- year-old-plant) of Coffea arabica, were extracted with ethanol $50 \%(\mathrm{v} / \mathrm{v})$, raw material/ solvent rate $-1 / 20 \mathrm{~m} / \mathrm{v}$, for 1 hours, under reflux. The extracts were frozen until analysis.

HPTLC analysis for caffeine and polyphenols. A densitometric (qualitative for polyphenols and qualitative and quantitative for caffeine) HPTLC analysis was performed according to TLC Atlas - Plant Drug Analysis (Wagner and Bladt, 1996). The polyphenolic fingerprint profile of the extracts was performed comparative for the samples and references substances (rutin, chlorogenic acid, caffeic acid, hyperoside $10^{-3} \mathrm{M}$; caffeine $1 \mathrm{mg} / \mathrm{ml}$ ) on a 10x10 Silica gel 60F254 HPTLC plate. The apparatus was a CAMAG LINOMAT 5 instrument. For spotting was used HamiltonBonaduz, Schweiz syringe. Ethyl acetate-acetic acid-formic acid-water 100:11:11:27 (v/v/v/v) was the mobile phase. After development, plates were dried. For caffeine the evaluation of the fingerprint was made at UV $=254 \mathrm{~nm}$, without derivatization and for polyphenols after derivatization in NP-PEG reagent at UV $=366 \mathrm{~nm}$, with a WinCats and VideoScan software. For linearity was applied different volumes of the standard caffeine solution $(1 \mathrm{mg} / \mathrm{ml})$ $(0.8,1.1,1.5,1.8$ and $2 \mu \mathrm{l})$. Correlation coefficient $R^{2}=0.986$. Linear regression equation was $y=8152.1 x+272.9$, where $\mathrm{y}$ is the peak area and $\mathrm{x}$ is the concentration. The results were expressed as grams of caffeine per 100gram.

Quantitative analytical determination. Total phenol content was determined according to European Pharmacopoeia 6.0, with Folin-Ciocalteu method. In a $25 \mathrm{ml}$, volumetric flask was transferred $1 \mathrm{ml}$ of extract, $10 \mathrm{ml}$ of water and $1 \mathrm{ml}$ of Folin Ciocalteu reagent. With $5 \%$ sodium carbonate $(\mathrm{w} / \mathrm{v})$, the volume has been made to $25 \mathrm{ml}$. The blend was left at room temperature for 30 minutes. The absorbance was read at $760 \mathrm{~nm}$ with a UV/VIS spectrophotometer (Helios $\lambda$, Thermo Electron Corporation), for all the samples. As blank was used distilled water. Total phenol content was determined with the linear regression line $\left(y=0.052 x-0.020\right.$, correlation coefficient $\left.R^{2}=0.992\right)$, obtained for gallic acid. The results were expressed as grams of gallic acid equivalents (GAE) per 100gram.

Free radical scavenging assay. The DPPH (Sigma-Aldrich) scavenger activity was performed according to SanchezMoreno, et.al. 1998. $2950 \mu$ l of the methanolic DPPH solution $(0.025 \mathrm{~g} / \mathrm{L})$ was mixed with $50 \mu \mathrm{l}$ of the extracts (concentration 1-1000 $\mu \mathrm{g} / \mathrm{ml}$ in ethanol $50 \mathrm{v} / \mathrm{v}$ ). The measurement was made in UV absorbance at $517 \mathrm{~nm}$. The blank solution was prepared with the same amount of methanol and DPPH. The solutions were measured after vigorously shaken and standing at r.t. for 30 minutes. Gallic acid methanolic solution (1\%) was used as positive control.

The radical scavenging activity was calculated with formula:

$\%$ inhibition $=[(\mathrm{AB}-\mathrm{AA}) / \mathrm{AB}] \times 100$.

$\mathrm{AB}$ - absorption of blank sample; AA - absorption of tested extract solution. The lower absorbance of the reaction mixture, indicated higher free radical activity.

The IC 50 value of the sample (concentration of sample required to inhibit $50 \%$ of the DPPH free radical) was calculated using Log dose inhibition curve.

Statistical Analysis. The results have been expressed as means \pm S.D, and the difference was tested by Student's t-test. The experiments were repeated three times. 


\section{RESULTS AND Discussions}

The HPTLC phenolic screening of coffee leaves, green and roasted beans show the presence of caffeoyl-quinic acids, comparative with references substances. HPTLC fingerprints of coffee leaves $(2,3)$, green beans $(4,5)$, roasted beans $(6,7)$ extracts reveals four prominent fluorescence-quenching zones in the Rf range 0.5-0.9 as caffeoyl and dicaffeoyl quinic acids ( $R f \sim 0.56$ for chlorogenic acid). The presence of rutin (Rf 0.45), hyperoside (Rf 0.73) and caffeic acid (Rf 0.98) was not determined. (Figure 1). The qualitative analysis of the coffee plant fruits and leaves, shown that the composition is similar.

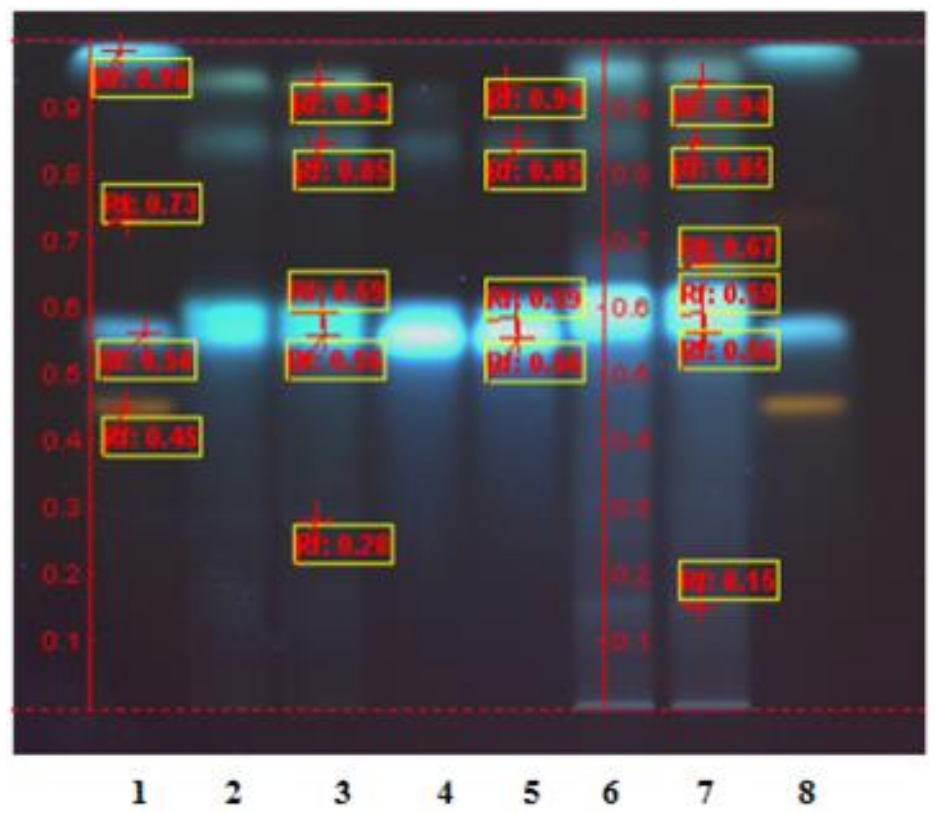

Figure 1: HPTLC phenolic fingerprint of Coffea arabica extracts. Track 1, 8 rutin, hyperoside, chlorogenic acid and caffeic acid (ref.); Track 2, 3 leaves extract (duplicate sample); Track 4, 5 green beans extract (duplicate sample), Track 6, 7 roasted beans extract (duplicate sample).

The caffeine content in coffee plant depends on the part of the plant that is analysed. Caffeine content in leaves, green and roasted beans of Coffea arabica by HPTLC, was made both for qualitative and quantitative determination.

The chromatograms revealed the presence of caffeine, in all three extracts, comparative with the reference substance (Rf 0.71).

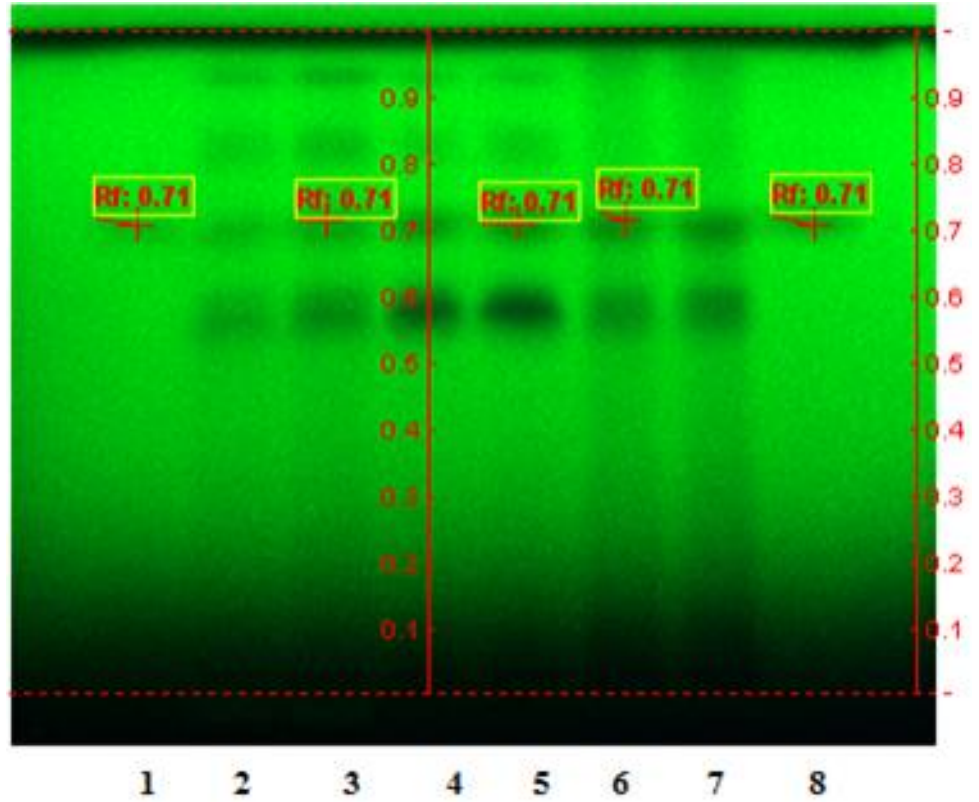

Figure 2: HPTLC for caffeine fingerprint of Coffea arabica extracts. Track 1, 8 caffeine (ref.); Track 2, 3 leaves extract (duplicate sample); Track 4, 5 green beans extract (duplicate sample), Track 6, 7 roasted beans extract (duplicate sample). 
Caffeine is a methylxanthine alkaloid, heat stabile, with bitter characteristics (maximum $10 \%$ of the bitterness of the coffee beverage) (Flament, I. et al., 1968). The caffeine content in the samples decreased from roasted beans to green beans and leaves of Coffea arabica ethanolic $(50 \% \mathrm{v} / \mathrm{v})$ extracts (Table 1$)$.

During the roasting process, an important number of reaction take place, the reactions that change the composition of the beans. The transformation of compounds includes destruction of some and formation of new ones, including chemicals with bioactive properties. During roasting, the content of caffeine is not significantly modified (Farah, A. 2012).

Table 1: Caffeine content in Coffea arabica extracts

\begin{tabular}{|l|c|}
\hline \multicolumn{1}{|c|}{ Extract } & Caffeine $\mathbf{( g / 1 0 0 g )}$ \\
\hline Leaves & 0.7 \\
\hline Green beans & 1.2 \\
\hline Roasted beans & 1.8 \\
\hline
\end{tabular}

Depending on the roasted process (blend, roasting degree, roasting method) the phenolic composition is changed, expecially for chlorogenic acids that are thermal unstable (Duarte, G., Farah, A. 2009; Farah, A., Donangelo 2006; Farah, A. 2012).

Table 2 presents the total phenolic content (TPC) in the extract obtained from leaves, green and roasted beans ethanolic $(50 \% \mathrm{v} / \mathrm{v})$. The leaves have the highest content in TPC expressed as gallic acid equivalent $(\mathrm{g} / 100 \mathrm{~g})$. The roasting process has led to a decrease in TPC content in roasted beans comparative with the green ones.

Table 2. Total phenolic compounds content in Coffea arabica extracts

\begin{tabular}{|l|c|}
\hline \multicolumn{1}{|c|}{ Extract } & Total phenolic compounds (g (GAE)/100g) \\
\hline Leaves & 12 \\
\hline Green beans & 9.8 \\
\hline Roasted beans & 4.6 \\
\hline
\end{tabular}

Dpph is a stable free radical that have the ability to decolorize in the presence of compounds with antioxidant properties. Dpph method is a rapid and easy way to determine, in chemical systems, the antioxidant activity of extracts. The results are presented as IC50 value of the sample (concentration of sample required to inhibit $50 \%$ of the DPPH free radical).

Table 3 present IC50 value for the extracts obtained comparatively with references substance gallic acid for four dilution to concentration between $1-1000 \mu \mathrm{g} / \mathrm{ml}$. The results are presented as mean $\pm \mathrm{SD}$ (for $\mathrm{n}=3$ ).

Table 3: IC50 values for Coffea arabica extracts comparative with gallic acid reference

\begin{tabular}{|l|c|c|}
\hline \multicolumn{1}{|c|}{ Extract } & IC50 $\boldsymbol{\mu g} / \mathbf{m l}$ & $\boldsymbol{R}^{\mathbf{2}}$ \\
\hline Leaves & 2,5 & 0,995 \\
\hline Green beans & 2,8 & 0,998 \\
\hline Roasted beans & 3,2 & 0,989 \\
\hline Gallic acid & 4 & 0,992 \\
\hline
\end{tabular}

The resultes shows that all the extracts have antioxidant potential and are correlated with the TPC (Table 2). The highest antioxidant potential was shown by the coffee leaves. Scavenger potential of the coffee extracts decreased as follows: leaves - green beans - roasted beans.

\section{CONCLUSION}

In terms of polyphenols and caffeine, the qualitative analysis of fruits (green or roasted) and leaves of coffee the content appears to be similar. The amount of polyphenols in leaves is the highest one comparative with the other extracts analysed. In the same time, the leaves appear to have the smallest quantity of caffeine. Roasted coffee beans have the highest content in caffeine and the lowerest in polyphenols. Antioxidant activity was correlated with the 
content in total phenolic composition. The data obtained from this study can be a first step for further investigations of coffee leaves, because of the higher antioxidant capacity and the lower content in caffeine. The consumption of coffee leaves (as tea) or as raw material for food supplement industry (extracts) can be health beneficial.

\section{REFERENCES}

Adrian J, Frangne R. Synthesis and availability of niacin in roasted coffee. Adv Exp Med Biol. 1991;289:49-59. Review.

Ashihara Hiroshi Coffee in Health and Disease Prevention Chapter 3 - Plant Biochemistry: Trigonelline Biosynthesis in Coffea arabica and Coffea canephora 2015, Pages 19-28).

Ballesteros LF, Cerqueira MA, Teixeira JA, Mussatto SI. Characterization of polysaccharides extracted from spent coffee grounds by alkali pretreatment. Carbohydr Polym. 2015 Aug 20;127:347-54.;

Clarke R.J., Macrae R. , Coffee: Physiology, Springer Science \& Business Media, Dec 31, 1988;

Dong W, Tan L, Zhao J, Hu R, Lu M. Characterization of Fatty Acid, Amino Acid and Volatile Compound Compositions and Bioactive Components of Seven Coffee (Coffea robusta) Cultivars Grown in Hainan Province, China. Molecules. 2015 Sep 14;20(9):16687-708;

Duarte, G., Farah, A. Chlorogenic acids and lactones in Brazilian commercial coffee. Proc. 22nd Int. Conf. Coffee Sci. ASIC/Prospero, 224-227. 2009. Trieste, Italy;

Dupas, C. J., Marsset-Baglieri, A. C., Ordonaud, C. S., Ducept, F. M. G. and Maillard, M.-N. (2006), Coffee Antioxidant Properties: Effects of Milk Addition and Processing Conditions. Journal of Food Science, 71: S253-S258;

Farah Adriana, Duarte Giselle Coffee in Health and Disease Prevention, Chapter 87-Bioavailability and Metabolism of Chlorogenic Acids from Coffee 2015, Pages 789-801 )

Farah, A., Donangelo, C. M. Phenolic compounds in coffee. Braz. J. Plant Physiol. 2006, 18, 26-36;

Farah, A. (2012) Coffee Constituents, in Coffee: Emerging Health Effects and Disease Prevention (ed Y.-F. Chu), Wiley-Blackwell, Oxford, UK).

Flament, I., Gautschi, F., Winter, M., Willhalm, B., Stoll, M. Les composants furanniques de l'ar^ome cafe: quelques aspects chimiques et spectroscopiques. Proc. 3rd Coll. Int. Coffee Sci. ASIC, 197-215.1968. Paris

Folstar P, van der Plas HC, Pilnik W, de Heus JG. Tocopherols in the unsaponifiable matter of coffee bean oil. J Agric Food Chem. 1977 Mar-Apr;25(2):283-5.)

Ochiai R, Sugiura Y, Shioya Y, Otsuka K, Katsuragi Y, Hashiguchi T. Coffee polyphenols improve peripheral endothelial function after glucose loading in healthy male adults. Nutr Res. 2014 Feb;34(2):155-9).,

Preedy Victor R. Caffeine: Chemistry, Analysis, Function and Effects Royal Society of Chemistry, 2012 -

Sanchez-Moreno, C. Larrauri, J.A., Saura-Calixto, F., 1998. A procedure to measure the antiradical efficiency of polyphenols. Journal of Agricultural and Food Chemistry 76, 270-276

Somporn C, Kamtuo A, Theerakulpisut P, Siriamornpun S. Effect of shading on yield, sugar content, phenolic acids and antioxidant property of coffee beans (Coffea Arabica L. cv. Catimor) harvested from north-eastern Thailand. J Sci Food Agric. 2012 Jul;92(9):1956-63.

Tuomilehto J. [Coffee and health]. Duodecim. 2013;129(13):1398-405;

Wagner H., Bladt S., 1996. Plant Drug Analysis, Second Edition, Springer.

$$
--0 \text {-- }
$$


